TITLE:

\title{
Formation of Si Nanowires by Direct Electrolytic Reduction of Porous SiO Pellets in Molten $\mathrm{CaCl}$
}

\section{$\operatorname{AUTHOR}(S)$ :}

Nishimura, Yusaku; Nohira, Toshiyuki; Kobayashi, Katsutoshi; Hagiwara, Rika

\section{CITATION:}

Nishimura, Yusaku ... [et al]. Formation of Si Nanowires by Direct Electrolytic Reduction of Porous SiO Pellets in Molten $\mathrm{CaCl}$. Journal of The Electrochemical Society 2011, 158(6): E55.

\section{ISSUE DATE:}

2011

URL:

http://hdl.handle.net/2433/258956

\section{RIGHT:}

This is the Accepted Manuscript version of an article accepted for publication in Journal of The Electrochemical Society. The Electrochemical Society and IOP Publishing Ltd are not responsible for any errors or omissions in this version of the manuscript or any version derived from it. The Version of Record is available online at

https://doi.org/10.1149/1.3575635.; This is not the published version. Please cite only the published version.; この論文 は出版社版でありません。引用の際には出版社版をご確認ご利用ください。 


\title{
Formation of Si Nanowires by Direct Electrolytic Reduction of Porous $\mathrm{SiO}_{2}$ Pellets in Molten $\mathrm{CaCl}_{2}$
}

\author{
Yusaku Nishimura, Toshiyuki Nohira," Katsutoshi Kobayashi, Rika Hagiwara \\ Department of Fundamental Energy Science, Graduate School of Energy Science, \\ Kyoto University, Yoshida-hommachi, Sakyo-ku, Kyoto 606-8501, Japan
}

\begin{abstract}
The effects of starting material and catalyst on the morphology of produced Si have been investigated for the direct electrolytic reduction of porous $\mathrm{SiO}_{2}$ pellets in molten $\mathrm{CaCl}_{2}$ at $1123 \mathrm{~K}$. The $\mathrm{Si}$ nanowires (SiNWs) were produced using amorphous $\mathrm{SiO}_{2}$ pellets with a tetrapod-like microstructure as the starting material, whereas plate-like Si was obtained from pellets made of spherical fumed $\mathrm{SiO}_{2}$. The $\mathrm{SiNWs}$ showed irregular branching and a wide distribution of diameters as the electrolysis proceeded. On the other hand, elongated SiNWs were formed during the electrolysis of pellets comprised of $\mathrm{Au}$ nanoparticles (AuNPs) and tetrapod-like microstructured $\mathrm{SiO}_{2}$ powder. This suggests that AuNPs work as catalysts for longitudinal nanowire growth in the present electrolytic process.
\end{abstract}

\footnotetext{
* Corresponding author. Tel.: +81 75753 5827; fax: +81 757535906.

E-mail address: nohira@energy.kyoto-u.ac.jp (T. Nohira).
} 
Silicon nanowires (SiNWs) have been drawing significant attention due to their unique electrical and optical properties. ${ }^{1,2}$ For instance, they are expected to be applied as building blocks for next-generation electronic and electrical devices (e.g., transistors, chemical sensors, photovoltaic cells, and thermoelectric devices). ${ }^{1-11}$ Recently, SiNWs were investigated and recognized as high-performance anodes for lithium secondary batteries. ${ }^{12}$ Silicon is considered to be a promising anode material, even though there are some serious problems associated with $\mathrm{Si}$ anodes including a large volume change and pulverization during multicycle charge-discharge processes. The use of SiNWs overcomes these issues by accommodating large volume changes and strains. For such applications, it is not necessary to prepare well-defined SiNWs, as required for next-generation electrical devices, because semiconducting properties are not related with the anode performance. For the use of SiNWs as an anode material, lower cost production is more important. In addition, if the content of oxygen in the SiNWs can be controlled, this would be a remarkable advantage because $\mathrm{SiO}_{x}$ has been reported to possess superior cyclability even in particle form probably due to the alleviation of host volume expansion. ${ }^{13}$

Thus far, various fabrication methods for SiNWs have been proposed. ${ }^{14-20}$ These can be classified into two categories, bottom-up and top-down processes. A typical 
method for a bottom-up process is the vapor-liquid-solid (VLS) method, first proposed by Wagner et al., ${ }^{14}$ wherein metal particles, such as $\mathrm{Au}, \mathrm{Ag}$, and Fe, work as catalysts to facilitate nanowire growth during hydrogen reduction of $\mathrm{SiCl}_{4}$, Later, Lieber et al. proposed a new process combining the VLS method with laser ablation. ${ }^{15}$ Meanwhile, Lee et al. found that SiNWs also form by oxide-assisted nanowire growth without the presence of a metal catalyst at temperatures below $1173 \mathrm{~K}$, which is much lower than the operational temperature for Fe-catalyzed nanowire growth (above $1423 \mathrm{~K}$ ). ${ }^{16}$ Korgel et al. proposed the production of SiNWs both in supercritical fluids ${ }^{17}$ and in an organic solution at atmospheric pressure. ${ }^{18}$ This solution process uses metal nanocrystals as catalysts and silicon hydrides as precursors. On the other hand, as an example of a top-down process, SiNW arrays can be produced by the electroless deposition of noble metals on a Si substrate in HF solutions containing metal ions. ${ }^{19}$ Although each of these processes have their own specific merits, they have a serious common problem, in terms of high production cost, due to the necessity needing to use energy-consuming equipment, high-purity expensive and explosive $\mathrm{Si}$ precursors, or high-purity $\mathrm{Si}$ substrates. In addition, it is difficult for these processes to control the oxygen content in SiNWs. 
In this study, we applied an electrochemical process in a molten salt to the production of SiNWs, a potentially low-cost process. We found that direct electrolytic reduction of insulating $\mathrm{SiO}_{2}$ is possible in molten $\mathrm{CaCl}_{2}$ at $1123 \mathrm{~K}$, yielding crystalline Si having a microscopic rod-like structure..$^{21-24}$ This reaction can be expressed as:

$$
\left.\mathrm{SiO}_{2}(\mathrm{~s})+4 \mathrm{e}^{-} \text {(in conductors }\right) \rightarrow \mathrm{Si}(\mathrm{s})+2 \mathrm{O}^{2-}\left(\text { in molten } \mathrm{CaCl}_{2}\right)
$$

Here, the electrons are supplied through electrical conductors (e.g., metal wires and the produced $\mathrm{Si}$ ) to solid $\mathrm{SiO}_{2}{ }^{21}$ In this method, control of the oxygen content in $\mathrm{Si}$ is expected, since the starting raw material is $\mathrm{SiO}_{2}$ and the oxygen activity in $\mathrm{Si}$ or $\mathrm{SiO}_{x}$ can be controlled by the electrolysis potential. ${ }^{25}$ The key factors controlling this process are the diffusion of $\mathrm{O}^{2-}$ ions in molten $\mathrm{CaCl}_{2}$ from the reaction front to the bulk melt and the microstructure of the formed $\mathrm{Si}$ which transports electrons to the reaction front. ${ }^{22}$ In light of the above, we assumed that the microstructure of the produced $\mathrm{Si}$ should be controllable by changing the microstructure of the starting $\mathrm{SiO}_{2}$. In actuality, we found that SiNWs are formed in the direct electrolytic reduction process of porous $\mathrm{SiO}_{2}$ pellets having specific microstructures. ${ }^{24}$ Independent of our work, Yang et al. also reported the formation of $\mathrm{SiNWs}$ from nanometer-sized $\mathrm{SiO}_{2}$ in molten $\mathrm{CaCl}_{2}{ }^{26}$ However, these methods had the problem of irregular branching due to the high mobility of $\mathrm{Si}$ atoms at the operational temperature $(1123-1173 \mathrm{~K})$. In order to 
overcome this problem and facilitate longitudinal growth of SiNWs, in the present study, the optimum condition for fabrication of SiNWs was investigated using pelletized $\mathrm{SiO}_{2}$ powders. First, the effect of the microstructure of the starting $\mathrm{SiO}_{2}$ pellets on the microstructure of the produced $\mathrm{Si}$ was investigated. The microstructure and porosity of the starting $\mathrm{SiO}_{2}$ were varied by utilizing two types of $\mathrm{SiO}_{2}$ powders with different morphologies. Second, the effect of the addition of $\mathrm{Au}$ nanoparticles (AuNP) to $\mathrm{SiO}_{2}$ was examined, anticipating promotion of longitudinal growth of the SiNWs.

\section{Experimental}

$\mathrm{CaCl}_{2}$ (300 g, 99+\%, Kojundo Chemical Laboratory Co., Ltd.) was used for the electrolytic bath. It was placed in an alumina crucible $\left(99.5 \% \mathrm{Al}_{2} \mathrm{O}_{3} ; \mathrm{SSA}-\mathrm{S}\right.$ grade, Nikkato Corp.) and dried in a vacuum at $473 \mathrm{~K}$ for more than $48 \mathrm{~h}$. Subsequently, it was gradually heated to $773 \mathrm{~K}$. All the experiments were carried out under an Ar atmosphere in a sealed quartz holder with a stainless steel flange at $1123 \mathrm{~K}$. The temperature was measured with a chromel-alumel thermocouple covered with a high-purity alumina tube (O.D. $6.0 \mathrm{~mm}, 99.5 \% \mathrm{Al}_{2} \mathrm{O}_{3}$; SSA-S grade, Nikkato Corp.) and maintained using an electric furnace (Isuzu Seisakusho Co., Ltd., RR-16K). 
The working electrode was composed of $\mathrm{a} \mathrm{SiO}_{2}$ pellet and a Mo wire $(0.2 \mathrm{~mm}$ in diameter, $99.95 \%$, Nilaco Corp.) as the lead material. Two types of powdery amorphous $\mathrm{SiO}_{2}$ were selected: (i) $\mathrm{SiO}_{2}$ produced by an alkali dissolution and neutralization precipitation process (abbreviated hereafter as $\mathrm{SP}-\mathrm{SiO}_{2}, \mathrm{SP}$ means "solution processed", $99.999 \%)^{27,28}$ and (ii) fumed-SiO 2 (99.999\%, Kojundo Chemical Laboratory Co., Ltd.). $\mathrm{SiO}_{2}$ pellets were prepared by compressing $\mathrm{SiO}_{2}$ powder at a pressure of $2.9 \times 10^{8} \mathrm{~N}$ $\mathrm{m}^{-2}$ and sintering in a vacuum at $1273 \mathrm{~K}$ for $10 \mathrm{~min}$ in a high-frequency induction furnace (Sekisui Chemical Co., Ltd., MU-1700). Macroscopic and microscopic views of the $\mathrm{SP}-\mathrm{SiO}_{2}$ and fumed-SiO 2 are shown in Fig. 1 (A, a) and (B, b), respectively. A pellet of the $\mathrm{SP}-\mathrm{SiO}_{2}$ powder has a tetrapod-like microstructure and a porosity of $70 \%$, whereas that of the fumed- $\mathrm{SiO}_{2}$ has a spherical microstructure and a porosity of $61 \%$. In some experiments, AuNPs (Sumitomo Electric Industries, Ltd.) were mixed with $\mathrm{SP}-\mathrm{SiO}_{2}$ powders before preparing the pellets. Electrical contacts were formed by winding a Mo wire around the $\mathrm{SiO}_{2}$ pellet. The counter electrode was a vitreous carbon rod, and the reference electrode was prepared by immersing an Ag wire $(1.0 \mathrm{~mm}$ in diameter, 99.95\%, Nilaco Corp.) in $\mathrm{CaCl}_{2}$ containing $0.5 \mathrm{~mol} \% \mathrm{AgCl}$ (99.5\%, Wako Pure Chemical Co., Ltd.) set in a mullite tube (O.D. $6.0 \mathrm{~mm}, 56 \% \mathrm{Al}_{2} \mathrm{O}_{3}-40 \% \mathrm{SiO}_{2} ; \mathrm{HB}$ grade, Nikkato Corp.). ${ }^{25}$ A $\mathrm{Ca}^{2+} / \mathrm{Ca}$ electrode was produced by in situ $\mathrm{Ca}$ 
electrodeposition on a Mo wire. All the potentials in this paper are given with reference to the $\mathrm{Ca}^{2+} / \mathrm{Ca}$ potential.

Electrolysis was performed with a potentiostat/galvanostat (Hokuto Denko Co., Ltd., HZ-5000) connected to a personal computer. Samples were prepared by electrolysis at $1.00 \mathrm{~V}$, as in our previous studies. ${ }^{21-23,25}$ After the electrolysis, the samples were rinsed in distilled water, and the Mo wire was removed allow for analysis of the pellet. The samples were characterized by X-ray diffraction (XRD, Rigaku Corp., Multiflex, Cu Ka, 50 kV, 40 mA), micro-Raman spectroscopy (Horiba Jobin Yvon Inc., LabRAM300), and field-emission-type scanning electron microscopy (FE-SEM, JEOL Ltd., JSM-6500F).

\section{Results and Discussion}

Characterization by XRD. - Electrolysis at $1.00 \mathrm{~V} v s$. $\mathrm{Ca}^{2+} / \mathrm{Ca}$ in molten $\mathrm{CaCl}_{2}$ at $1123 \mathrm{~K}$ for just 10 min caused a change in color from white or gray to dark brown on the pellet surface (Fig. 1A-D). The dark brown substance produced by the electrolysis was macroscopically characterized by XRD. Figure 2 compares an XRD pattern of the pellet with those of an original $\mathrm{SiO}_{2}$ pellet and standard crystalline $\mathrm{Si}$. The XRD data confirm that crystalline $\mathrm{Si}$ is produced by the electrolysis of a $\mathrm{SiO}_{2}$ pellet in molten 
$\mathrm{CaCl}_{2}$. In addition, $\mathrm{CaCl}_{2}$ was revealed to be sufficiently removed by the present washing procedure.

Observation by SEM. - SEM observations were conducted to investigate the effect of the microstructure of the starting $\mathrm{SiO}_{2}$ on that of the formed crystalline $\mathrm{Si}$. As shown in Fig. 1a-d, rod-like nanostructured silicon ( $\mathrm{SiNW}$ ) was formed from the tetrapod-like $\mathrm{SP}-\mathrm{SiO}_{2}$, while plate-like structured silicon was obtained from the spherical fumed-SiO 2 . In the present process, the microstructure of $\mathrm{Si}$ was formed through the removal of $\mathrm{O}^{2-}$ ions, shrinkage of the volume, and aggregation of electrochemically formed $\mathrm{Si}$ atoms. The initial tetrapod-like microstructure of $\mathrm{SiO}_{2}$ may prevent aggregation of $\mathrm{Si}$ atoms in directions perpendicular to the rod axis, as revealed by the moderate intervals between adjacent $\mathrm{SiO}_{2}$ stems. Hence, for the production of SiNWs, it would be preferable to use the tetrapod-like $\mathrm{SP}-\mathrm{SiO}_{2}$ as a starting material. It should also be noted that a number of SiNWs were produced by electrolysis of $\mathrm{SP}_{-} \mathrm{SiO}_{2}$ for as short a time as 10 min without any special treatment, as shown in Fig. 3. The morphological variation of the $\mathrm{SiNW}$ from the $\mathrm{SP}-\mathrm{SiO}_{2}$ pellets was then investigated using FE-SEM. Figure 4 indicates the time evolution $(5,10$, and $15 \mathrm{~min})$ of the microstructure and diameter distribution of SiNWs produced by the electrolysis of 
$\mathrm{SP}-\mathrm{SiO}_{2}$ pellets. All the micrographs were taken around the points where the pellets had been in contact with Mo wires. The micrographs reveal that SiNWs grow thicker and longer as the electrolysis proceeds. The average diameter was approximately $100 \mathrm{~nm}$ for the 10-min electrolysis. After the 60-min electrolysis, as shown in Fig. 5, Si wires (or rods) larger than $1 \mu \mathrm{m}$ in diameter were the main products. The increase in the size of the SiNWs is likely caused by the relatively high mobility of Si atoms at the experiment temperature $(1123 \mathrm{~K})$. Thus, it is considered that longer SiNWs may be produced by using the tetrapod-like structure with larger pores and thinner $\mathrm{SiO}_{2}$ stems and also by shortening the electrolysis period with increased contact points between $\mathrm{SiO}_{2}$ and Mo.

Micro-Raman spectroscopy. - SEM observation provides direct but localized information on morphological changes in the samples. Micro-Raman spectroscopy was also performed to obtain average and complementary information on the growth process of the SiNWs. Figure 6 shows the Raman spectra of the SiNWs produced by electrolysis of $\mathrm{SP}-\mathrm{SiO}_{2}$ at $1.00 \mathrm{~V}$ in molten $\mathrm{CaCl}_{2}$ at $1123 \mathrm{~K}$ for various electrolysis durations. These spectra were also measured around the points at which the pellets had been in contact with Mo wires. The samples were excited by a $\mathrm{He}-\mathrm{Ne}$ laser at a power sufficiently low to prevent temperature elevation. The sample produced by short-period 
electrolysis exhibits an asymmetric broad peak at a wavenumber smaller than $520 \mathrm{~cm}^{-1}$, at which the monocrystalline bulk Si has a peak assigned to optical phonons. According to the phonon confinement model proposed by Richter et al. ${ }^{29}$ and Campbell et al., ${ }^{30}$ the more minute nanostructured Si exhibits a larger peak shift in the smaller wavenumber direction. In Fig. 6, the peak position is slightly lower for a shorter electrolysis period, indicating that the average size of the SiNWs increased as the electrolysis proceeded. This result is consistent with SEM observations.

Effect of Au nanoparticles.- Although SiNWs were produced in the above experiment, some irregular branching was observed. Promotion of longitudinal growth was attempted by mixing AuNPs into the original $\mathrm{SiO}_{2}$ powder. This was done using a concept similar to the metal-catalyzed nanowire processes, as schematically illustrated in Fig. 7. At the operational temperature $(1123 \mathrm{~K})$, pure Si exists in its solid phase. However, alloying with Au lowers the melting point, which leads to the formation of liquid droplets of the Au-Si alloy. In the VLS process, the $\mathrm{Si}$ atoms produced are captured preferentially on liquid $\mathrm{Au}-\mathrm{Si}$ alloy droplets present at the tips of the nanowires. An increase in the concentration of the $\mathrm{Si}$ in the $\mathrm{Au}-\mathrm{Si}$ alloy shifts the binary system to the region of coexistence of liquid alloy and solid Si. The deposition of 
solid Si takes place preferentially on a tip of a SiNW due to the lowest surface energy at this location. A similar phenomenon is expected to occur in the electrolysis of a $\mathrm{Au}-\mathrm{SiO}_{2}$ pellet. Figure 8 shows SEM micrographs of SiNWs after 10-min electrolysis at $1.00 \mathrm{~V}$. More elongated nanowires are seen in the micrograph for an $\mathrm{Au}-\mathrm{SiO}_{2}$ pellet, compared to those for an $\mathrm{SiO}_{2}$ pellet. Thus, as expected, longitudinal growth was clearly facilitated by the addition of AuNPs.

\section{Conclusions}

The formation of SiNWs was confirmed in the direct electrolytic reduction of tetrapod-like $\mathrm{SP}-\mathrm{SiO}_{2}$ in molten $\mathrm{CaCl}_{2}$ at $1123 \mathrm{~K}$. On the other hand, plate-like silicon was obtained from the pellet made of spherical fumed-SiO 2 . The average diameter of SiNWs was approximately $100 \mathrm{~nm}$ for the 10 -min electrolysis of $\mathrm{SP}_{-} \mathrm{SiO}_{2}$. The issue of irregular branching, observed for $\mathrm{SP}-\mathrm{SiO}_{2}$ pellets, was circumvented by adding AuNPs to the $\mathrm{SP}-\mathrm{SiO}_{2}$ pellets. It is considered that the AuNPs work as a catalyst for longitudinal nanowire growth in the present electrolytic process.

The SiNWs produced in the present process should be useful as anodes in lithium secondary batteries since the entire SiNWs have good electrical connectivity, since they are formed in an electrolytic process. Thus, it is guaranteed that the entire nanowires 
produced in this process can be utilized as electrodes. In addition, AuNPs used as catalysts are not only inert substances, but they can also aid conduction in the batteries.

Based on the above points, $\mathrm{SiNW}$ production from inexpensive high-purity $\mathrm{SiO}_{2}$ powder with nanometal catalysts should provide future possibilities for realizing low-cost production of SiNWs and their applications.

\section{Acknowledgements}

This work was supported by the Industrial Technology Research Grant Program in 2007 from the New Energy and Industrial Technology Development Organization (NEDO) of Japan. 


\section{References}

1. W. Lu and C. M. Lieber, J. Phys. D: Appl. Phys., 39, R387 (2006).

2. M. Law, J. Goldberger, and P. Yang, Annu. Rev. Mater. Res., 34, 83 (2004).

3. B. M. Kayes, H. A. Atwater, and N. S. Lewis, J. Appl. Phys., 97, 114302 (2005).

4. B. Tian, X. Zheng, T. J. Kempa, Y. Fang, N. Yu, G. Yu, J. Huang, and C. M. Lieber, Nature, 449, 885 (2007).

5. $\quad$ L. Hu and G. Chen, Nano Lett., 7, 3249 (2007).

6. L. Tsakalakos, J. Balch, J. Fronheiser, B. A. Korevaar, O. Sulima, and J. Rand, Appl. Phys. Lett., 91, 233117 (2007).

7. A. P. Goodey, S. M. Eichfeld, K.-K. Lew, J. M. Redwing, and T. E. Mallouk, J. Am. Chem. Soc., 129, 12344 (2007).

8. E. C. Garnett and P. Yang, J. Am. Chem. Soc., 130, 9224 (2008).

9. T. Stelzner, M. Pietsch, G. Andrä, F. Falk, E. Ose, and S. Christiansen, Nanotech., 19, 295203 (2008).

10. A. I. Hochbaum, R. Chen, R. D. Delgado, W. Liang, E. C. Garnett, M. Najarian, A. Majumdar, and P. Yang, Nature, 451, 163 (2008).

11. A. I. Boukai, Y. Bunimovich, J. Tahir-Kheli, J.-K. Yu, W. A. Goddard III, and J. R. Heath, Nature, 451, 168 (2008). 
12. C. K. Chan, H. Peng, G. Liu, K. McIlwrath, X. F. Zhang, R. A. Huggins, and Y. Cui, Nat. Nanotechnol., 3, 31 (2008).

13. J. Yanga, Y. Takeda, N. Imanishi, C. Capiglia, J. Y. Xie and O. Yamamoto, Solid State Ionics, 152-153, 125 (2002).

14. R. S. Wagner and W. C. Ellis, Appl. Phys. Lett., 4, 89 (1964).

15. A. M. Morales and C. M. Lieber, Science, 279, 208 (1998).

16. R.-Q. Zhang, Y. Lifshitz, and S.-T. Lee, Adv. Mater., 15, 635 (2003).

17. J. D. Holmes, K. P. Johnston, R. C. Doty, and B. A. Korgel, Science, 287, 1471 $(2000)$

18. A. T. Heitsch, D. D. Fanfair, H.-Y. Tuan, and B. A. Korgel, J. Am. Chem. Soc., 130, $5436(2008)$.

19. K.-Q. Peng, Y.-J. Yan, S.-P. Gao, and J. Zhu, Adv. Mater., 14, 1164 (2002).

20. H. F. Yan, Y. J. Xing, Q. L. Hang, D. P. Yu, Y. P. Wang, J. Xu, Z. H. Xi, and S. Q. Feng, Chem. Phys. Lett., 323, 224 (2000).

21. T. Nohira, K. Yasuda, and Y. Ito, Nat. Mater., 2, 397 (2003).

22. K. Yasuda, T. Nohira, K. Amezawa, Y. H. Ogata, and Y. Ito, J. Electrochem. Soc., 152, D69 (2005). 
23. K. Yasuda, T. Nohira, K. Takahashi, R. Hagiwara, and Y. H. Ogata, J. Electrochem. Soc., 152, D232 (2005).

24. Y. Nishimura, T. Nohira, K. Yasuda, Y. Fukunaka, and R. Hagiwara, Trans. MRSJ, 35(1), 47 (2010).

25. K. Yasuda, T. Nohira, R. Hagiwara, and Y. H. Ogata, J. Electrochem. Soc., 154, E95 (2007).

26. J. Yang, S. Lu, S. Kan, X. Zhang, and J. Du, Chem. Commun., 3273 (2009).

27. M. Bessho, Y. Fukunaka, H. Kusuda, and T. Nishiyama, Energy \& Fuels, 23, 4160 (2009).

28. H. A. Aulich, K. H. Eisenrith, and H. P. Urbach, J. Mater. Sci., 19, 1710 (1984).

29. H. Richter, Z. P. Wang, and L. Ley, Solid State Commun., 39, 625 (1981).

30. I. H. Campbell and P. M. Fauchet, Solid State Commun., 58, 739 (1986). 


\section{Figure captions}

Figure 1. Photographs and SEM micrographs of pellets before and after electrolysis at $1.00 \mathrm{~V}$ for $10 \mathrm{~min}$ in molten $\mathrm{CaCl}_{2}$ at $1123 \mathrm{~K}$. (A,a) Original $\mathrm{SP}-\mathrm{SiO}_{2}$, (B,b) electrolyzed $\mathrm{SP}_{-} \mathrm{SiO}_{2},(\mathrm{C}, \mathrm{c})$ original fumed-SiO , and (D, d) electrolyzed fumed-SiO${ }_{2}$.

Figure 2. XRD patterns of a pellet made of $\mathrm{SP}_{-} \mathrm{SiO}_{2}$ (a) before and (b) after electrolysis at $1.00 \mathrm{~V}$ for $60 \mathrm{~min}$ in molten $\mathrm{CaCl}_{2}$ at $1123 \mathrm{~K}$. The reference XRD pattern of (A) $\mathrm{Si}$ (JCPDS no. 27-1402) is also shown for comparison.

Figure 3. An SEM image of SiNWs produced by the electrolysis of $\mathrm{SP}_{-} \mathrm{SiO}_{2}$ at $1.00 \mathrm{~V}$ in molten $\mathrm{CaCl}_{2}$ at $1123 \mathrm{~K}$.

Figure 4. Time evolution of the microscopic structure of SiNWs produced by the electrolysis of $\mathrm{SP}_{-} \mathrm{SiO}_{2}$ at $1.00 \mathrm{~V}$ in molten $\mathrm{CaCl}_{2}$ at $1123 \mathrm{~K}$. The electrolysis durations were (a) 5, (b) 10, and (c) 15 min.

Figure 5. SEM images of $\mathrm{Si}$ microstructures produced by the electrolysis of $\mathrm{SP}-\mathrm{SiO}_{2}$ at $1.00 \mathrm{~V}$ in molten $\mathrm{CaCl}_{2}$ at $1123 \mathrm{~K}$ for $60 \mathrm{~min}$. 
Figure 6. Raman spectra of $\mathrm{SiNW}$ s produced by the electrolysis of $\mathrm{SP}_{-} \mathrm{SiO}_{2}$ at $1.00 \mathrm{~V}$ in molten $\mathrm{CaCl}_{2}$ at $1123 \mathrm{~K}$ for various electrolysis durations.

Figure 7. Phase diagram of the Au-Si binary system and the mechanism of SiNW growth catalyzed by an AuNP.

Figure 8. The effect of AuNPs on the microstructure of SiNWs produced by the electrolysis at $1.00 \mathrm{~V}$ in molten $\mathrm{CaCl}_{2}$ at $1123 \mathrm{~K}$. The pellets were made from (a) SP-SiO 2 only, and (b) $\mathrm{SP}_{-} \mathrm{SiO}_{2}$ with AuNPs. 

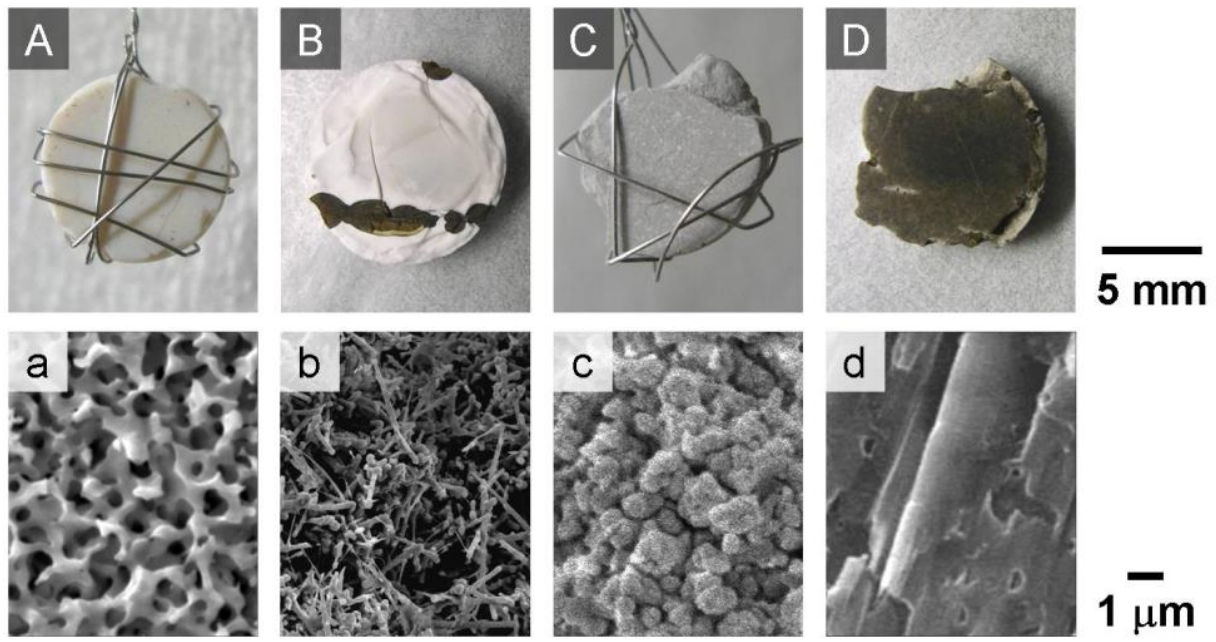

Figure 1. Y. Nishimura, T. Nohira, K. Kobayashi, R. Hagiwara. 


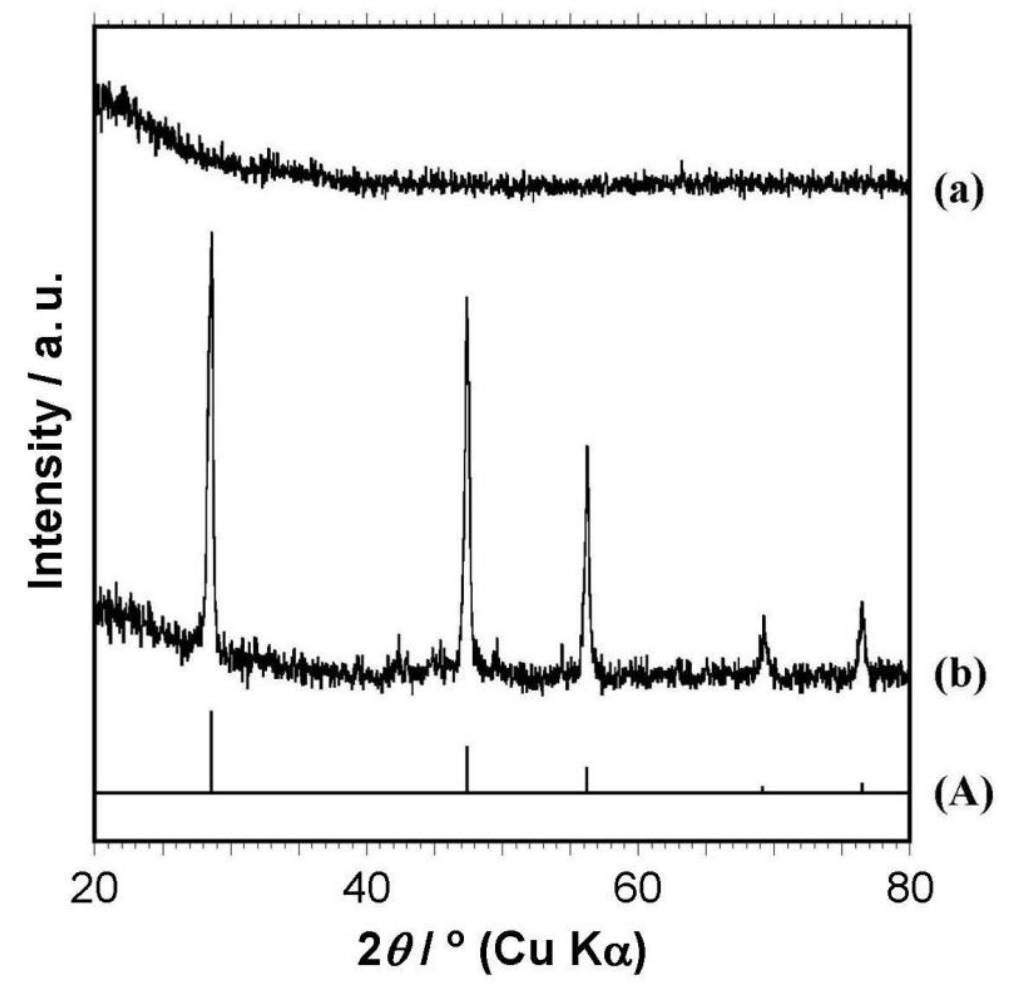

Figure 2. Y. Nishimura, T. Nohira, K. Kobayashi, R. Hagiwara. 


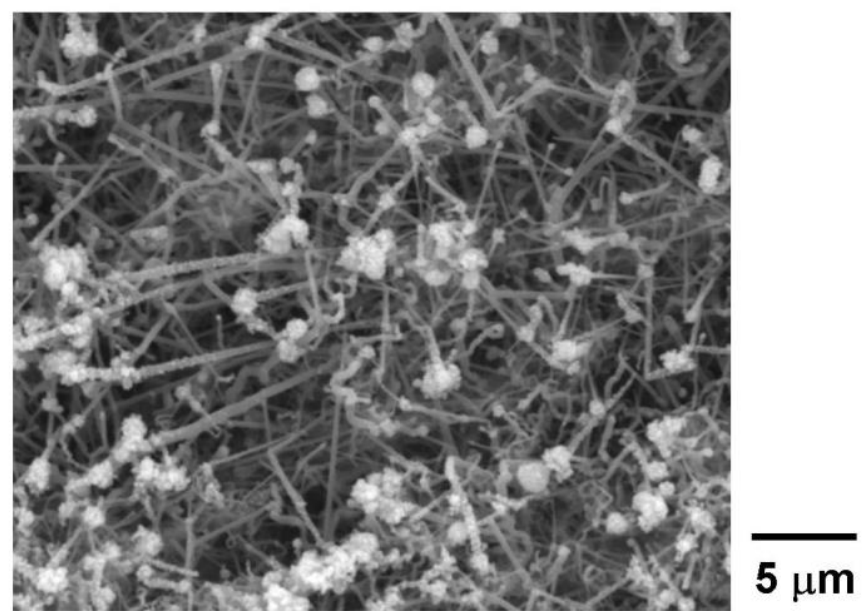

Figure 3. Y. Nishimura, T. Nohira, K. Kobayashi, R. Hagiwara. 

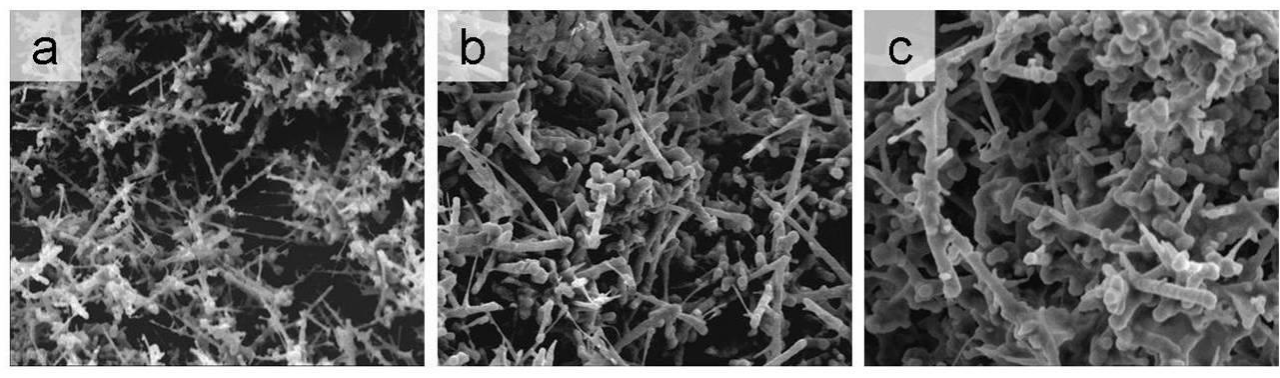

$500 \mathrm{~nm}$

Figure 4. Y. Nishimura, T. Nohira, K. Kobayashi, R. Hagiwara. 

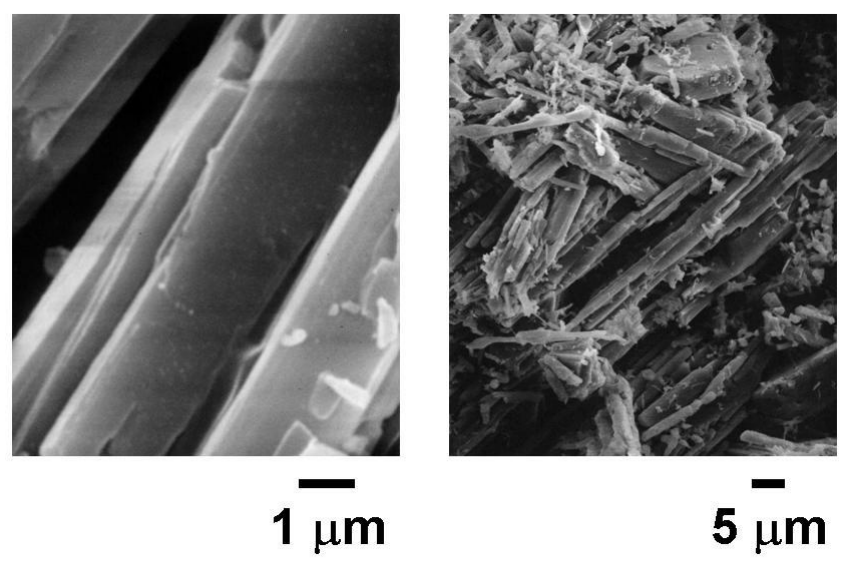

Figure 5. Y. Nishimura, T. Nohira, K. Kobayashi, R. Hagiwara. 


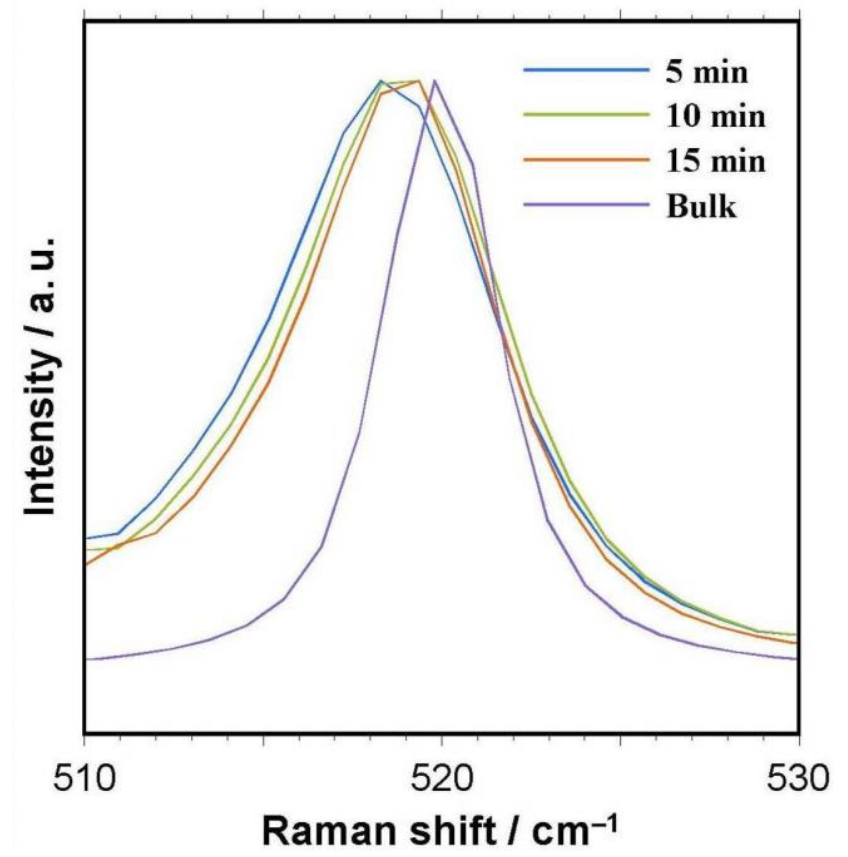

Figure 6. Y. Nishimura, T. Nohira, K. Kobayashi, R. Hagiwara. 

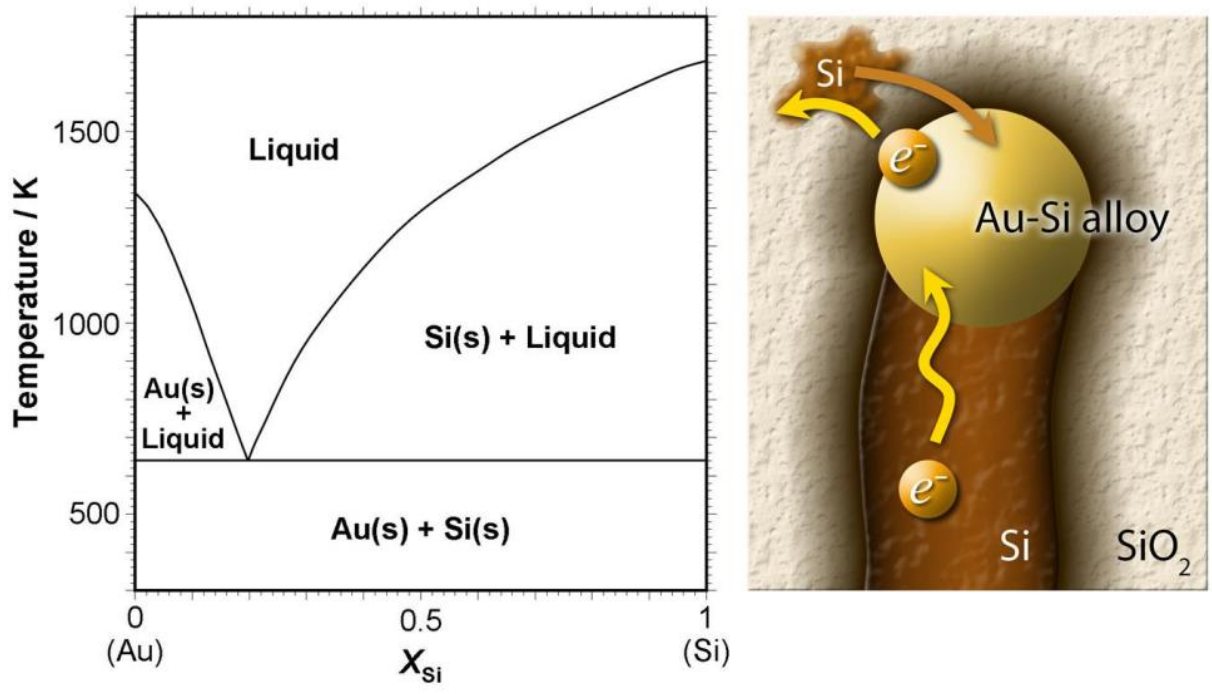

Figure 7. Y. Nishimura, T. Nohira, K. Kobayashi, R. Hagiwara. 

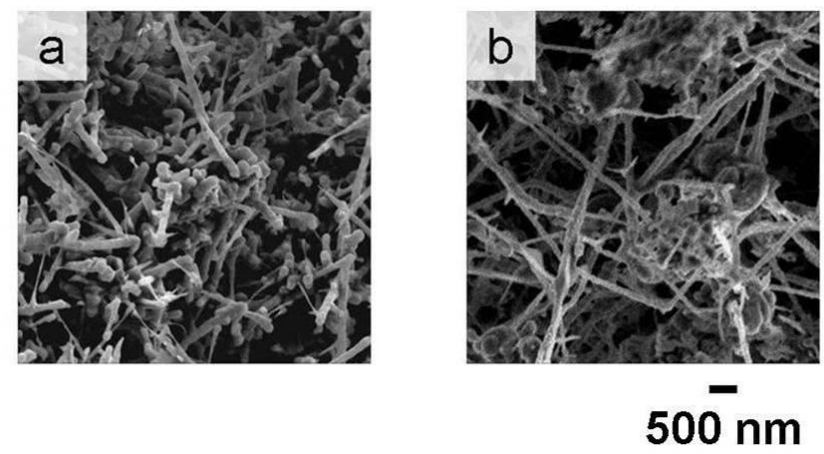

Figure 8. Y. Nishimura, T. Nohira, K. Kobayashi, R. Hagiwara. 